\title{
Research and Scholarship of Clinical Laboratory Science Faculty Members
}

\author{
KATHY V WALLER, JILL E CLUTTER, KAREN R KARNI
}

OBJECTIVES: To describe the research and scholarly productivity of faculty in four-year college and university clinical laboratory science (CLS) programs. To identify hours spent in research, numbers of presentations and publications, and external funding.

DESIGN: In 2008, a national study involving 106 college and university CLS programs was conducted to determine whether faculty were participating in research. A questionnaire, in electronic format, was distributed to 448 faculty members. Data from 2001 to 2008, and from 275 respondents (61\% response) representing 93 of 106 (88\%) CLS programs were analyzed.

SETTING: The study took place at The Ohio State University with collaboration from the University of Minnesota.

PARTICIPANTS: All CLS faculty within a four-year university or college sponsoring a NAACLS-accredited CLS program were invited to participate.

MAIN OUTCOME MEASURES: To determine whether CLS faculty scholarly activities have been strengthened in the past decade. To quantitate scholarship productivity. To assess faculty perceptions of their employment environments.

RESULTS: Data indicate that faculty who possess earned doctorates have higher levels of research productivity. While $52 \%$ of CLS faculty hold doctorates and $45 \%$ are tenured, $36 \%$ of all CLS faculty members have not published a research paper or abstract since 2001. On the other hand, 19\% have published 11 or more times. CLS faculty were also awarded a total of $\$ 62$ million in external funding, 83\% from government sources. Teaching remains a primary responsibility of many faculty members.
CONCLUSIONS: In the past decade, and generally speaking, CLS faculty have made some progress in scholarship including highest degree obtained, publications, presentations, and grantsmanship.

INDEX TERMS: Clinical laboratory science, research, faculty, scholarship.

Clin Lab Sci 2010;23(3);Suppl:3-32

Kathy V. Waller Ph.D., CLS(NCA), The Ohio State University, Columbus, $\mathrm{OH} 43210$

Jill E. Clutter, Ph.D., The Ohio State University, Columbus, $\mathrm{OH} 43210$

Karen R. Karni, Ph.D., CLS(NCA), Professor Emeritus University of Minnesota

Address for Correspondence: Kathy V. Waller Ph.D., CLS (NCA), Associate Professor, The Ohio State University, 535 Atwell Hall, 453 W. 10 th Avenue, Columbus, OH 43210, Waller.1@osu.edu, 614-2927303

\section{INTRODUCTION}

Since 1985, the first author of this study, together with colleagues, has investigated the research and scholarly activities of faculty in baccalaureate level programs in clinical laboratory science. ${ }^{1,2,3,4,5}$ As we stated in 1999, ${ }^{5}$ research and scholarly activities are often considered hallmarks of the establishment of a true profession. These activities validate professional practice standards and promote advancement of knowledge in the field. In academia, research is often an expectation of faculty and may be the major determinant in tenure and promotion decisions. 


\section{RESEARCH AND REPORTS}

$\mathrm{Hu}$ and Gill, reporting on the research productivity of information specialists, further state ${ }^{6} \ldots$ "it has become increasingly important for academicians to be more productive in their research fields. Being classified as a 'research university' is often perceived as an indication of quality programs, faculty and students. Very often such classification is based on the research productivity of faculty members or specific programs of a university."

This study addresses similar issues, with particular emphasis on: demographic characteristics of CLS faculty members; time allocated to research by faculty degree, rank, kind of employing institution, and tenure status; scholarly productivity of CLS faculty; external funding awarded to CLS faculty; hours spent each week in teaching; and perceptions of the research environment.

\section{MATERIALS AND METHODS}

The survey questionnaire used in the 1996 study of clinical laboratory science faculty ${ }^{4}$ was slightly modified in 2008 and adapted to an electronic format via SurveyMonkey ${ }^{\odot}$.

The questionnaire was divided into three sections. The first section sought individual demographic information, such as highest degree earned, current academic rank, tenure status, and type of employing institution. The second part identified each participant's involvement in various research activities to include time spent in research, numbers of publications, presentations, and grants awarded as well as hours spent in teaching. The final portion focused on perceptions of the research environment within each faculty member's employing institution.

The population surveyed included all faculty in National Accrediting Agency for Clinical Laboratory Sciences (NAACLS) accredited college and university based baccalaureate level CLS programs. Names and email addresses of all regular salaried faculty members were obtained, either by using an internet search, or by contacting the program director. In May of 2008, email cover letters together with an electronic link were mailed to 448 individuals from 106 programs, an average of 4.2 faculty per institution. Follow-up requests were sent to non-respondents in June and July. Responses were received from 275 of 448 (61\%) CLS faculty, representing 93 of 106 (88\%) programs.

Data were analyzed using SPSS 16.0 for Windows. For the purposes of this study, descriptive statistics and oneway ANOVA analyses are reported. The Scheffe post hoc test for multiple comparisons determined differences between groups. Consent to perform the investigation was obtained through the Institutional Review Board of The Ohio State University.

\section{RESULTS}

\section{Demographic Characteristics}

Demographic characteristics of the group are listed in Table 1. In 2008, 52 percent of CLS faculty held a doctorate degree and 54 percent were senior faculty (associate or full professors). Forty-five percent of the respondents were tenured, with 16 percent on a tenuretrack line, and for 39\%, tenure did not apply. The majority of respondents (55\%) were from 4-year colleges/universities, while $42 \%$ were employed by research universities. Most faculty (66\%) were on a 12 month full-time status. Fifty-three percent held a faculty position for 16 or more years and over threequarters were women. Seventy-two percent of respondents were 50 years of age and older, and 26\% were 60 or older.

Figure 1 shows the importance of research, teaching and service as perceived by faculty within their employing institutions. Two-thirds ranked teaching as most important, while 31 percent ranked research as most important.

\section{Involvement in Research Activities}

This section identified participants' involvement in scholarly activities between 2001 and mid-2008. It included the number of hours per week spent in research, numbers of research publications (articles and abstracts), and presentations, together with grants awarded.

When queried as to the number of hours spent in research each week, and in 2008, 29\% of faculty spent no time in research; $41 \%$ spent one to eight hours; $22 \%$ indicated nine to twenty hours; and $7 \%$ performed 21 


\section{RESEARCH AND REPORTS}

or more hours of research. Hours per week spent in research factored by degree, faculty rank, type of institution, and tenure status were measured. Faculty holding doctorates spent significantly more time in research than BS and MS degreed individuals. Professors spent significantly more time in research than

Table 1. Demographic Characteristics of CLS Faculty Respondents $-2008$

\begin{tabular}{|c|c|c|}
\hline Highest Level of Education & Frequency & $(\%)$ \\
\hline Baccalaureate & 14 & $(5.1)$ \\
\hline Masters & 118 & $(42.9)$ \\
\hline Doctorate & 143 & $(52.0)$ \\
\hline \multicolumn{3}{|l|}{ Academic Rank } \\
\hline Instructor/Lecturer & 41 & $(14.9)$ \\
\hline Assistant Professor & 85 & $(30.9)$ \\
\hline Associate Professor & 91 & $(33.1)$ \\
\hline Professor & 58 & $(21.1)$ \\
\hline \multicolumn{3}{|l|}{ Tenure Status } \\
\hline Tenured & 124 & $(45.1)$ \\
\hline Tenure Track & 44 & $(16.0)$ \\
\hline Tenure does not apply & 107 & $(38.9)$ \\
\hline \multicolumn{3}{|l|}{ Type of Employing Institution } \\
\hline 4-year major research university & y 114 & $(41.6)$ \\
\hline 4-year college/university & 150 & $(54.7)$ \\
\hline Other & 10 & $(3.6)$ \\
\hline \multicolumn{3}{|l|}{ Current Employment Status } \\
\hline Full-time, 9 months & 77 & $(28.0)$ \\
\hline Full-time, 12 months & 182 & $(66.2)$ \\
\hline Part-time & 16 & $(5.8)$ \\
\hline \multicolumn{3}{|l|}{ Years in Faculty Position } \\
\hline 1 to 7 & 75 & $(27.6)$ \\
\hline 8 to 15 & 52 & $(19.1)$ \\
\hline 16 to 23 & 70 & $(25.7)$ \\
\hline$>24$ & 75 & $(27.6)$ \\
\hline \multicolumn{3}{|l|}{ Level of students taught } \\
\hline Baccalaureate & 271 & $(100)$ \\
\hline Masters & 104 & $(37.8)$ \\
\hline Doctorate & 37 & $(13.5)$ \\
\hline \multicolumn{3}{|l|}{ Academic Role } \\
\hline Faculty & 161 & $(58.5)$ \\
\hline Director or Chair & 90 & $(32.7)$ \\
\hline Education Coordinator & 10 & (3.6) \\
\hline Other & 14 & $(5.1)$ \\
\hline \multicolumn{3}{|l|}{ Gender } \\
\hline Female & 213 & $(77.5)$ \\
\hline Male & 62 & $(22.5)$ \\
\hline \multicolumn{3}{|l|}{ Age - years } \\
\hline$<40$ & 28 & $(10.4)$ \\
\hline $40-49$ & 47 & $(17.4)$ \\
\hline $50-59$ & 126 & $(46.6)$ \\
\hline $60-65$ & 57 & $(21.2)$ \\
\hline$>66$ & 12 & $(4.4)$ \\
\hline
\end{tabular}

instructors/lecturers. Tenure track individuals spent significantly more time in research than tenured faculty as well as "tenure not applicable" individuals. However, tenured individuals spent significantly more time in research than "tenure not applicable" faculty. There was no significant difference for number of hours of research by type of institution.

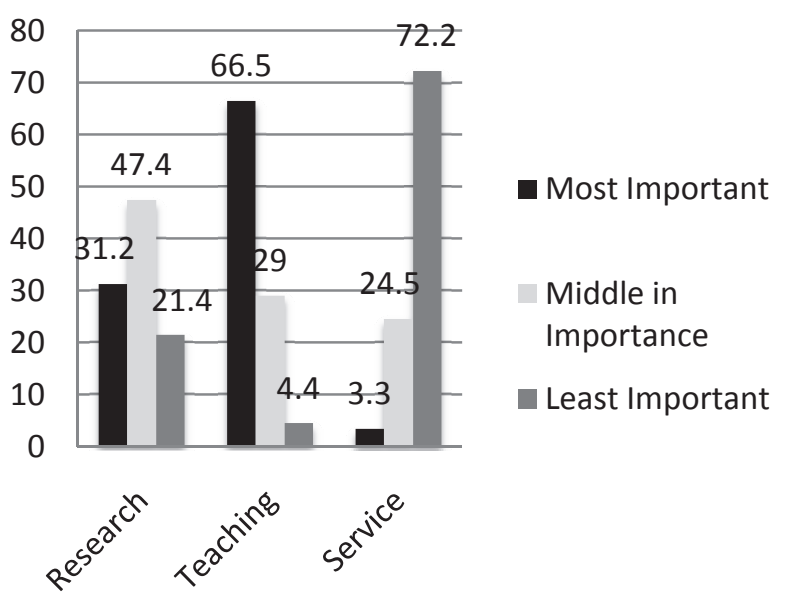

Figure 1. Faculty Perceptions of the Importance of Research, Teaching, and Service in their Employing Institutions

For research articles and abstracts in refereed journals as first or co-author, $36 \%$ of the respondents had never published a research article or abstract; $31 \%$ had published one to five; $14 \%$ published six to ten; and $19 \%(\mathrm{n}=53)$ had published 11 or more times. The numbers of research publications were significantly higher for doctoral faculty than faculty holding a MS or BS degree. Professors published significantly more than assistant professors and instructors/lecturers, but not statistically more than associate professors. Tenured and tenure track individuals published significantly more than "tenure does not apply" faculty members. There were no significant differences between tenured and tenure track faculty for numbers of research publications, nor between types of institutions.

For presentations, $24 \%$ of the respondents had never given a presentation; $26 \%$ had presented one to five times; $16 \%$ six to ten times; and $34 \%(n=93)$ had given 11 or more presentations. Data for total presentations depicts scientific and research papers, poster sessions, case studies, brief presentations, panel discussions, and non-research symposia given at state, 


\section{RESEARCH AND REPORTS}

national, and international levels. Tenured, doctoral faculty at the level of professor provided significantly more presentations. There were no statistically significant differences between type of institution and number of presentations.

Time spent in teaching was not significantly different by degree, rank, institution type, nor tenure status. On average, all CLS faculty spent 22 hours each week teaching.

Data on the number of CLS faculty awarded external funding, together with sources of such funding were collected and totaled $\$ 62$ million. Between 2001 and 2008, the majority (83\%) of funding originated from government sources. Forty-seven percent of faculty received some kind of external funding and 9.5\% $(n=26)$ garnered grants in excess of $\$ 500,000$, with $20 \%$ $(n=55)$ awarded from $\$ 100,000$ to one million dollars or more. Doctoral faculty received significantly more funding than MS faculty. Professors were awarded significantly more grant monies than instructor/ lecturers. There was no significant difference for total grant monies by type of institution nor tenure status.

\section{Perceptions of the Research Environment}

Table 2 shows the faculty members' perceptions of their own research environments. Computer accessibility and the importance of research for promotion and tenure decisions ranked first and second as characteristics of the environment. Resources (including finances and time) were seen by faculty as being least present in their environments.

\section{DISCUSSION}

Our data show that CLS faculty members holding a doctorate make up $52 \%$ of all faculty in 4-year NAACLS accredited institutions. This percentage is smaller than faculty members in such allied health programs as health administration (80\%), speech language pathology and audiology (70\%), or physical therapy $(67 \%) .^{7}$ But, CLS faculty with doctorates are considerably more than those in dental hygiene (12\%), radiography $(12 \%)$, or physician assistant $(18 \%)$, while somewhat similar to faculty in dietetics $(59 \%)$ or occupational therapy $(54 \%){ }^{7}$
In clinical laboratory science, $53 \%$ of faculty have been in their positions for more than 16 years, and $72 \%$ are 50 years old or more. These findings are of concern, and the graying of the professoriate has grown in size. Our studies confirm anecdotal reports that suggest we may lose at least one quarter of our CLS faculty in the next five years.

Figure 1 depicts faculty members' perceptions of the importance of research, teaching, and service in their own institutions. While $42 \%$ of respondents were employed in a research institution, only $31 \%$ of all respondents thought that research was most important. In contrast, two-thirds believed that teaching to be most important. This may indicate that some faculty in research institutions (e.g. academic health centers) have not been provided clear expectations of their duties, or that their roles are, indeed, primarily in teaching. This finding also supports CLS faculty members' extensive involvement in teaching - an average of 22 hours each week, regardless of degree, rank, type of employing institution or tenure status. It also reinforces perceptions of their own research environments, in which "time available for research" ranked lowest with "research supported financially," ranking next to lowest (Table 2).

Table 2. Faculty Perceptions of the Characteristics of the Research Environment

\begin{tabular}{lcc}
\hline & Mean* & $\underline{\text { Rank }}$ \\
\cline { 2 - 3 } Characteristics & & 1 \\
Computer is accessible & 6.1 & 2 \\
Research is important for & 5.9 & \\
promotion/tenure & & 3.5 \\
Research is a priority & 5.6 & 3.5 \\
Research is rewarded & 5.6 & 5.5 \\
Research is supported by & 4.9 & \\
department/division & & 5.5 \\
Importance of research, teaching, & 4.9 & 7 \\
and service well defined & & 8 \\
Personally interested in research & 4.8 & 9 \\
Statistical services available & 4.6 & 10 \\
Research supported administratively & 4.4 & 11 \\
Institutional resources available & 4.1 & 12 \\
Research opportunities numerous & 3.8 & 13 \\
Research supported financially & 3.5 & \\
Research time available & 2.6 & \\
\hline
\end{tabular}

${ }^{*}$ Scale $=1($ Low $)$ to 7 (High) 


\section{RESEARCH AND REPORTS}

Time spent in research was greatest for those holding doctorates (averaging 10.5 hours each week), and at the rank of professor. These findings suggest that these persons are more experienced in performing research and have achieved their rank by previously successful research productivity. However, by tenure status, those on a tenure track spent the most time in research, implying that to achieve tenure they needed to perform research.

For research publications again, those with doctorates and who held the rank of professor produced the most articles and abstracts in refereed journals as first or coauthor. Again, these results are not surprising, indicating that individuals with doctorates and highest rank, are producing the most publications.

Presentations are correlated with publications, and again, those faculty with doctorates, highest rank, and tenured status had the greatest numbers of presentations.

It appears noteworthy, that once again, as in 1996, CLS faculty spent an average of 22 hours each week in teaching. This is a heavy teaching load. Hours spent in teaching did not differ significantly for type of employing institution, earned degree, or tenure status. These data may indicate, perhaps, that teaching is an essential component of most employment settings in higher education, whether located in research universities or in four-year colleges and universities. It may also reflect the small numbers of faculty in CLS baccalaureate programs, averaging only 4.2 faculty members per program.

Being awarded external funding is important, not only to faculty members, and their reputations, but also to their employing institutions. Here, we find that 55 faculty (20\%) received $\$ 100,000$ or more from 2001 to mid-2008. Sixteen $(5.8 \%)$ received $\$ 1,000,000$ or more during this time frame. Total numbers funded, at some level, were $\$ 62$ million by 131 individuals (48\%). These figures indicate that more CLS faculty are being awarded more monies than before $(\$ 23$ million in 1996)..$^{5}$ The major source of funding in 2008 was the government ( $\$ 51$ million), at $83 \%$. As might be expected, those holding doctorates and with the rank of professor garnered the most funding. However, neither tenure status not type of institution was significant.

Faculty perceptions of the characteristics of their research environments reinforce the importance of research in their institutions. While computer accessibility ranked first in their work places in 2008, the statements "research is important for promotion and tenure, research is a priority, and research is rewarded" ranked 2 through 4 . Here we may have a disconnection - while teaching was ranked first in importance by twothirds of faculty participants, many of these same individuals ranked the importance of research very highly. Perhaps this may show an awareness that in their overall collegiate/university environment, research is considered important, but in their own programs, teaching is more important. Or, funding and/or time for research are lacking.

A 2001 study by Akroyd et. al. ${ }^{8}$ investigated the differences in attitudes of allied health faculty and deans regarding the importance and rewards of teaching and research. Faculty perceived teaching as more important than did deans. The authors concluded that faculty roles, expectations, and the appropriate reward and support system should be clearly delineated for both teaching and research.

A relatively new finding in this study was a lack of difference in research activities (time spent, publiccations, presentations, or funding) between faculty in research universities and those in non-research four-year colleges and universities. This has recently been an observation with commentaries in The Chronicle of Higher Education. For example, Ghodsee wrote a compelling piece regarding her accepting a position at a liberal arts college in Maine." She states, "in my own case, as a result of a lower teaching load, generous internal grants, and two years of junior leave to take advantage of external fellowships, I was able to do the research and writing for a second book and several peerreviewed journal articles. I successfully came up for tenure in my sixth year."

Her article prompted a number of letters to the editor including Raybeck's $\mathrm{s}^{10}$ comments, "I have spent my entire professional life in a liberal-arts setting, where I 


\section{RESEARCH AND REPORTS}

found research support, travel funds for meetings, and a personal - not bureaucratic - relationship with administrative officers. The result was a number of books, scores of articles, and an active engagement with my profession of anthropology."

Still, Taub ${ }^{11}$, a biologist, writes. . ."college professors in some disciplines appear better able than professors in other fields to approximate the research output of their colleagues at doctoral institutions. Faculty members in history did best, nearly matching the rate of their doctoral colleagues' scholarly publications: college professors of political science, communications, English and literature, philosophy and religion, and fine arts published more than two-thirds as much as did their peers at doctoral institutions. In contrast, faculty members in business, foreign languages, biology, physical sciences, and computer sciences published less than a third as many scholarly works as did their doctoral colleagues."

Our colleagues in clinical laboratory science may appear to have somewhat "bridged a gap" in research activities and productivity, concerning their own sites of employment. A number have been successful, regardless of setting.

Finally, attention must be paid to the Association of Schools of Allied Health Professions (ASAHP) for its ongoing advocacy and oversight of research activities among many allied health disciplines, including clinical laboratory science. More recently, ASAHP published a special article on the NAPRAH Symposium: Enhancing Faculty Research Career Development: Infrastructure and Mentoring Models. ${ }^{12}$ The National Alliance Promoting Research in Allied Health (NAPRAH) was formed in 2003 to assist the research capacity among the allied health professoriate.

Finally, Wise, Brotherton and Mitcham have offered an opinion in which teaching and service can enhance scholarship among faculty members. ${ }^{13}$ They state:

With heavy teaching loads and service expectations, many allied health faculty members find themselves in situations that limit their ability to engage in traditional research and scholarship of sufficient magnitude to meet institutional standards for promotion and tenure. Strategies that link teaching or service activities to scholarly productivity increase the potential for allied health faculty to build credible forms of scholarship and find their niche in the academy.

Thus, good teaching and good service can lead to good scholarship.

\section{CONCLUSION}

Clinical laboratory science faculty from both research institutions and four-year colleges and universities, have made progress in earning doctorates, and in their own research activities including time spent in research, publications, presentations and grantsmanship. Those holding doctorates and senior faculty have been most successful in scholarly activities.

All faculty members, regardless of their employment setting, spend an average of 22 hours per week in teaching, perhaps precluding some from a more active involvement in scholarly pursuits. The CLS professoriate is also graying, and possibly one-quarter may retire within the next five years. These circumstances call for our advocating and nurturing potential faculty - particularly in research, to join our ranks.

\section{REFERENCES}

1. Flanigan KS, Ballinger PW, Grant $\mathrm{HK}$ et al. Research productivity profile of allied health faculty. J Allied Health 1988; 17:87-100.

2. Waller KV, Jordan L, Gierhart J et al. Research skills and the research environment: a needs assessment of allied health faculty. J Allied Health 1988;17:101-13.

3. Waller KV, Schiller MR, Snyder JR. A profile of medical technology educators' scholarly productivity and research environment. Lab Med 1988;19:655-60.

4. Waller KV, Wyatt D, Karni KR. Research productivity and activities of clinical laboratory science faculty: a follow-up study. J Allied Health 1998;27:142-9.

5. Waller KV, Wyatt D, Karni KR. Scholarly activities among clinical laboratory science faculty. Clin Lab Sci 1999;12:19-27.

6. Hu Q, Gill TG. IS faculty research productivity: influential factors and implications. Inf Resources Manage J. 2000;13:1525 . 


\section{RESEARCH AND REPORTS}

7. Association of Schools of Allied Health Professions. Institutional Profile Survey Report. 2007-2009. 4400 Jenifer St. NW, Washington D.C. 20015.

8. Akroyd D, Bamberg WR, Wilson SL et al. Differences in attitudes regarding teaching and research orientations between allied health faculty and administrators in academic health centers. J Allied Health 2001;30:61-7.

9. Ghodsee K. A research career at a liberal-arts college. Available from http://chronicle.com/weekly/v54/i33/33c00101.htm Accessed 2009 May 28.

10. Raybeck D. The liberal-arts college as a home for research. Letters to the editor. Available from http://chronicle.com/ weekly/v54/i37/37a03102.htm Accessed 2009 May 28.
11. Taub D. The liberal-arts college as a home for research. Letters to the editor. Available from http://chronicle.com/weekly/ v54/i37/37a03102.htm Accessed 2009 May 28.

12. Neiman GS, Craik R, Delitto A et al. NAPRAH SYMPOSIUM: Enhancing faculty research career development: infrastructure and mentoring models. J Allied Health 2007:36:e-179-91.

13. Wise HH, Brotherton, SS, Mitcham MD. From scholarly teaching to the scholarship of teaching: A retrospective look at strategies that foster the transition of scholarly work in allied health into credible forms of scholarship. J Allied Health 2008;37:e-50-68.

The peer-reviewed Research and Reports Section seeks to publish reports of original research related to the clinical laboratory or one or more subspecialties, as well as information on important clinical laboratory-related topics such as technological, clinical, and experimental advances and innovations. Literature reviews are also included. Direct all inquiries to David $L$ McGlasson MS, MLS, 59th Clinical Research Division/SGRL, 2200Berquist Dr., Bldg. 4430, Lackland AFB TX 782369908, david.mcglasson@lackland.af.mil

Clinical Laboratory Science encourages readers to respond with thoughts, questions, or comments regarding these articles. Email responses towestminsterpublishers@comcast.net. In the subject line, please type the journal issue and lead author such as "CLIN LAB SCI 23(3) SUPPL: RE WALLER". Selected responses may appear in the Dialogue and Discussion section in a future issue. Responses may be edited for length and clarity. We look forward to hearing from you. 